\title{
STEFAN SOMMER
}

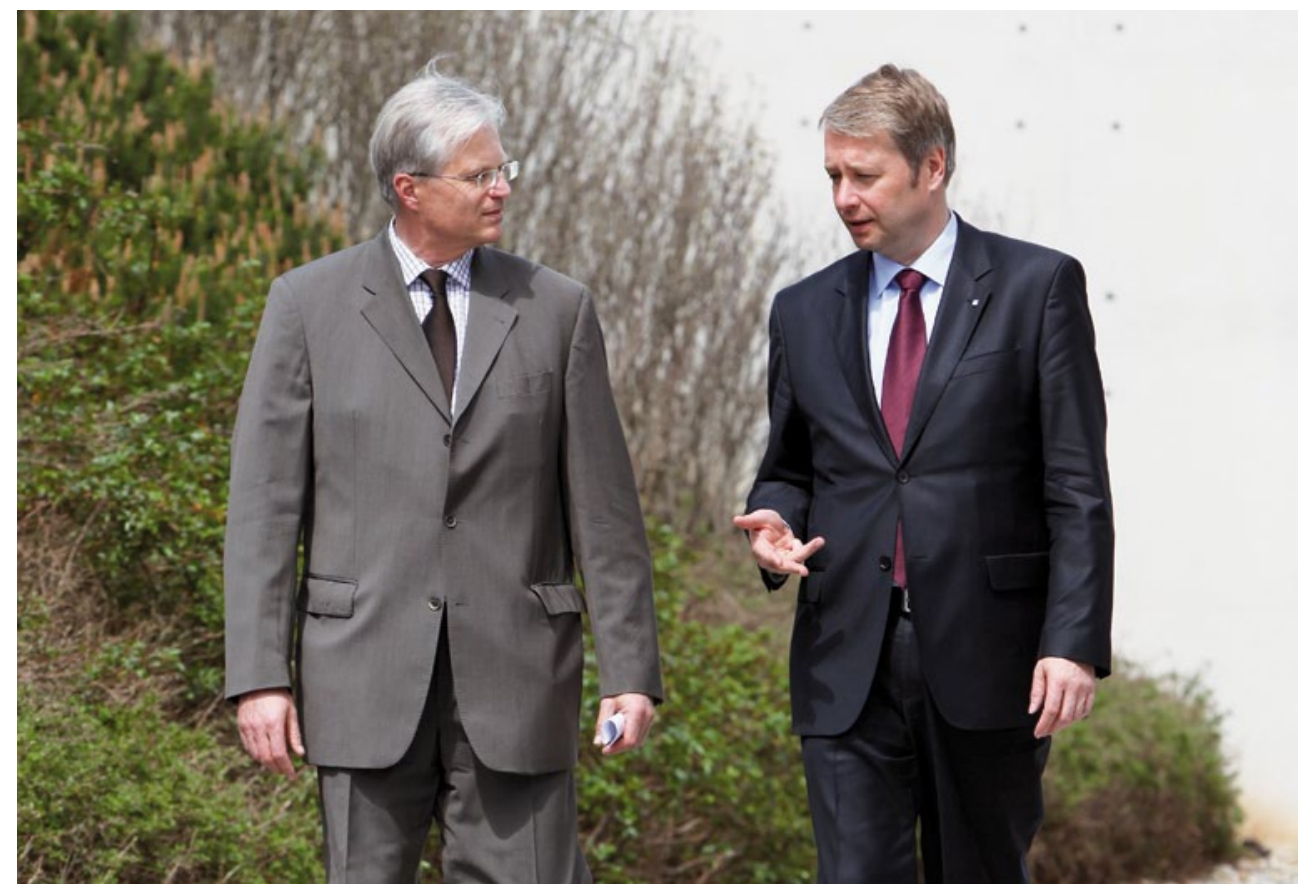

Dr. Stefan Sommer, seit 1. Mai 2012 Vorstandsvorsitzender der ZF Friedrichshafen AG, zur Elektromobilität: „Wir werden die Bandbreite komplett abdecken. Kunden, die an einem Systemansatz interessiert sind, werden diesen von ZF erhalten. Wir werden aber auch die dafür entwickelten Komponenten verfeinern.“

BILD @ ZF

\section{„ICH WERDE DEN EINGESCHLAGENEN WEG FORTSETZEN UND VERFEINERN“}

Als „Tag der Arbeit“ wird der 1. Mai 2012 Stefan Sommer sicher in Erinnerung bleiben. Schließlich ist der 49-jährige promovierte Maschinenbauingenieur seitdem neuer ZF-Chef. Der 1963 im Sternzeichen Steinbock geborene Sommer spricht eindringlich, in mittlerer Tonlage. Er ist waschechter Münsteraner, ein Mensch ohne Allüren - und bei ZF ein Senkrechtstarter. Der sympathische Dr.-Ing. ist der jüngste Vorstandschef von ZF. Seine Vision? „Ich werde den von meinem Vorgänger Hans-Georg Härter eingeschlagenen Weg fortsetzen und verfeinern. Weiter entwickeln möchte ich ZF im Bereich von neuen Technologien und auf die Öffnung zu neuen Märkten hin.“

\section{„SICHERLICH KANN MAN NICHT KONTINUIERLICH ZWEISTELLIG WACHSEN“}

Zum Sternzeichen Steinbock liest man: „Sein Vordringen zu einem gesteckten Ziel ist so unerbittlich und stetig wie ein Lavastrom." Dies beweisen Sommers Karriereschritte: Er studierte Maschinenbau in Bochum und promovierte dort. 1994 stieg er bei ITT Automotive Europe als Entwicklungsingenieur ein. Von 1997 an verantwortete Sommer bei Continental Automotive Systems zunächst die Entwicklung von Elektronik und Sensorik, später die für elektronische Luftfedersysteme.

2003 übernahm Stefan Sommer bei Continental Temic die Leitung des Bereichs Insassenschutzsysteme. Anfang 2005 ging er zu Continental Automotive Systems, wo er den Bereich elektronische Bremssysteme leitete. 2008 wechselte Sommer zur ZF Sachs AG und übernahm dort das Vorstandsressort für den Bereich Fahrwerk, bevor er ab Oktober 2010 vom ZF-Aufsichtsrat zum Konzernvorstand für Materialwirtschaft berufen wurde.

\section{„DIE WEICHEN FÜR EIN WACHSTUM AUF 20 MILLIARDEN EURO SIND GESTELLT“}

In einem Punkt besteht Gewissheit: Tief unter Sommers ruhiger Oberfläche brennt ein geheimes Feuer. Und dies braucht er auch, schließlich steigt der Besitzer fünf luftgekühlter Porsche 911 in große Fußstapfen. Unter Hans-Georg Härter wuchs der Konzernumsatz von jährlich 11,6 auf 15,5 Milliarden, die Weichen für ein Wachstum auf 20 Milliarden bis 2015 sind gestellt. Und weil ein Steinbock zielstrebig ist, glaubt man Sommer auch, wenn er sagt: „Sicherlich kann man nicht kontinuierlich zweistellig wachsen. Das Wachstum auf 20 Milliarden Euro, das wir jetzt bis 2015 anstreben, gilt es abzusichern. Dem Unternehmen die Führung, die Substanz zu geben, dass man zu einem kontinuierlichen Wachstum kommt, sehe ich als eine meiner Kernaufgaben an.“

Seine eigentliche Bewährungsprobe steht Sommer aber noch bevor. Nämlich dann, wenn der Wachstumsmotor stockt. Aber auch dazu passt das Sternzeichen: Trifft den Steinbock Unheil oder Missgeschick, ist er zäh, widerstandsfähig und beginnt von vorn. 